\title{
Cerebral dominance for language in cerebral palsy
}

\author{
P. T. Q U I N N A N G A V I N A N D E W S
}

From the Human Communication Laboratory, University of New South Wales Teaching Hospitals, The Prince Henry Hospital, Sydney, Australia

S UMMARY A test of cerebral dominance for language was administered to 51 cerebral palsied adults. The test consisted of dichotically presented words and in normal speaking adults had previously demonstrated very marked right ear superiority, interpreted as left cerebral dominance. The group of cerebral palsied subjects did not show the predicted right ear superiority. This finding may represent a chance maldistribution of side of cerebral injury within the 51 subjects. If substantiated, however, it would suggest either that the cortical damage in cerebral palsy is commonly widespread or else that the inherent left cerebral dominance of neonates is less tenacious than is generally assumed.

Notwithstanding evidence of an anatomical basis for left cerebral language dominance (Geschwind and Levitsky, 1968; Witelson and Pallie, 1973; Wada, 1974), it is clear that serious injury to language-generative cortical tissue in infancy is followed by the development of language dominance in the previously non-dominant hemisphere (Basser, 1962; Branch et al., 1964). This fluidity of cerebral dominance has not been as clearly demonstrated in instances of less severe infantile injury. An investigation of the cerebral dominance of a group of cerebral palsied adults afforded an opportunity to examine this issue, and to clarify the extent of cerebral pathology in the cerebral palsied. In these subjects a variable degree of neonatal cortical morbidity-presumably randomly distributed between hemispheres-can be assumed. While this would tend to lower the degree of left cerebral dominance of the group as a whole, the likelihood that some individuals escaped the involvement of speech-generative areas would lead to the prediction of a residual, although abnormally reduced, group tendency to left cerebral dominance.

Despite the emergence of a multitude of new procedures, the estimation of cerebral dominance for language within a group still amounts to a choice between Wada intracarotid sodium amylobarbitone testing and the use of dichotic verbal tests. The Wada test, while providing valid estimates at an individual level, is almost invariably too onerous a procedure for non-clinical use. The value of dichotic testing, on the other hand, is Accepted 20 December 1976 limited by the small but undeniable margin of error between expected and apparent cerebral dominance, as evident from the large-scale dichotic testing of populations of right handers (Blumstein et al., 1975). Nevertheless, although the margin of error of these tests in assigning an individual's cerebral dominance is of the order of $10 \%$, they do retain considerable statistical potency when used to determine the overall dominance of a uniform group of adequate size. For example, a dichotic word test originally developed in this laboratory for use with stutterers (Quinn, 1972) has indicated a very highly significant mean right ear superiority $\left(P=2.2 \times 10^{-23}\right.$, $t$ test for paired data), interpreted as group mean left cerebral dominance, in a population of 72 right handed normal controls $(94 \%$ of individuals were right ear superior). Thus the loss of confidence in the indicated cerebral dominance of any given individual-in this instance perhaps $5 \%$ error-is compensated for by the massive degree of confidence in the indicated left cerebral dominance of the group as a whole.

The above dichotic test procedure has provided results which approximate more closely to predicted cerebral dominance rates than do the results of other dichotic tests used in this laboratory, and so it was selected for use in the present investigation.

\section{Method}

Details of the test procedure are reported elsewhere (Quinn, 1975). It involved the presentation 
of 12 dichotic trials to naïve subjects. Each trial consisted of six pairs of consonant-vowel-consonant (CVC) words presented over three seconds, with headphone reversals between each trial. Subjects were encouraged to strive for the highest possible number of correct words, and, throughout the experiment, no reference was made to the laterality aspects of the task. In previous studies subjects had reported in writing, but the presence of movement disorder and unintelligible speech among the cerebral palsied prompted a modified form of report. This consisted of a multiple-choice answer sheet, provided immediately after each trial, in which the 12 genuine words, written in letters $1.2 \mathrm{~cm}\left(\frac{1}{2}{ }^{\prime \prime}\right)$ high, were dispersed randomly among 12 other incorrect CVC words. Each correct selection scored one point for the appropriate ear, and each incorrect selection was scored as an error. There was considerable variation in the degree of physical handicap and, in the more severe cases, it was necessary for the experimenter to point to each of the 24 responses in turn while the subject responded with a prearranged signal. In this procedure there is a clear possibility that decay in memory storage may increase ear superiority (Quinn, 1975). Ideally this variability in response time should have been controlled but no appropriate control group or other adjustment could be devised.

Instead, an unselected group of nine able-bodied subjects performed the test using the modified form of report. Despite the small size of the group, the predicted right ear superiority was statistically significant $(P=<0.0005)$, and the rate of error selection was $11.7 \%$. It was concluded that the modified form of report had not grossly reduced the sensitivity of the test.

\section{Subjects}

The subjects were 62 male adults, aged 17-55 years, who work in a factory associated with the Spastic Centre of New South Wales. They had been selected by the staff there as being free of gross intellectual impairment or hearing loss. Their degree of physical impairment ranged from partial spastic hemiplegia with virtually normal speech to grossly handicapped subjects who were totally unintelligible and unable to point to the answer sheet. All were tested by pure-tone audiometry at frequencies of $500,1000,2000$, and 4000 $\mathrm{Hz}$, and the five subjects who had a discrepancy of greater than $5 \mathrm{~dB}$ between ears were not included in the final data analysis. A further six subjects were judged clinically to be incapable of satis- factorily obeying instructions (all apparently because of intellectual deficit rather than physical handicap) and testing was prematurely terminated. The data on the remaining 51 subjects were analysed.

\section{Results}

The results are shown in the Table. The mean left ear and right ear scores were 16.8 and 16.7 respectively. The mean laterality index $\left(\frac{R-L}{R+L}\right)$ was calculated. This statistic was expressed as a percentage and represents the degree of superiority of one ear over the other in terms of an individual's overall score. For the cerebral palsied population it was $3.6 \%$, right ear superior. Twentyfive subjects showed right ear advantage, 22 showed left ear advantage, and four showed equal ear scores.

Table Results of tests of cerebral dominance for language in 51 cerebral palsied patients

\begin{tabular}{|c|c|c|c|c|}
\hline Type of subject & $N$ & $\begin{array}{l}\text { Mean } \\
\text { ear score } \\
L \quad R\end{array}$ & $\begin{array}{l}\text { Laterality } \\
\text { index } \\
\left(\frac{R-L}{R+L}\right) \times \\
100 \%\end{array}$ & $\begin{array}{l}\text { Significance } \\
\text { of right ear } \\
\text { superiority } \\
\text { (t-test) }\end{array}$ \\
\hline \multirow{7}{*}{$\begin{array}{l}\text { Right handed normal } \\
\text { speakers (Quinn, 1975) } \\
\text { Right handed } \\
\text { stutterers (Quinn, 1975) } \\
\text { Normals unselected } \\
\text { for handedness* } \\
\text { Unselected normals } \\
\text { using multiple choice } \\
\text { report system } \\
\text { Non-right handed } \\
\text { normals (Quinn, 1975) } \\
\text { Cerebral palsied un- } \\
\text { selected for handedness } \\
\text { using multiple choice } \\
\text { report system }\end{array}$} & 72 & $7.3-22.5$ & $50.1 \%$ & $<0.0005$ \\
\hline & 73 & $8.1-19.2$ & $39.9 \%$ & $<0.0005$ \\
\hline & 62 & $9.0-21.7$ & $40.3 \%$ & $<0.0005$ \\
\hline & 9 & $124-27.1$ & $38.1 \%$ & $<0,0005$ \\
\hline & & & & \\
\hline & 13 & $9.3-20.4$ & $35.1 \%$ & $<0.01$ \\
\hline & 51 & $16.8-16.7$ & $3.6 \%$ & NS \\
\hline
\end{tabular}

* M. S. Armstrong (1976-personal communication).

\section{Discussion}

The error rate of $13.4 \%$, which would include genuine errors such as 'blush' for 'lush', was similar to that $(11.7 \%)$ of the able-bodied group who showed right ear superiority. This, and the fact that such a figure apportioned randomly between ears would not drastically alter any preexisting ear superiority, suggests that neither deliberate guessing nor modified report procedure can explain the absence of significant ear superiority in the cerebral palsy data.

The general failure of this group to show significant ear superiority is exemplified by the fact that 
the total number of left ear words reported by all 51 subjects (855) surpassed the total number of right ear words (852) by only three words. The mean laterally index of $3.6 \%$, right ear superior, contrasts strongly with those of a previously determined hierarchy of right handers, unselected normal speakers, and right handed stutterers (Table) which varied from 50 to $40 \%$. Even a small group of non-right handers had a laterality index of $35 \%$ (Quinn, 1975).

As noted above, it is not claimed that this test accurately identifies the dominance of any given individual, and so the absence of a group mean ear superiority in no way precludes the likelihood of a mix, within the group, of individuals with full cerebral dominance in either direction. Nevertheless, these results suggest an unexpected lack of left cerebral dominance for the group taken as a whole.

There are reasons for caution in interpreting this finding. Dichotic testing of other pathological populations elsewhere has led to premature reports of aberrant cerebral dominance. Furthermore, it is possible that the present group might by chance have contained several more individuals with predominantly left hemispheric damage than individuals with right sided lesions. Chance effects of this type would tend to abolish the predicted left cerebral dominance effect in the group mean scores.

Should the trends in the present data be substantiated, however, it would suggest either that cerebral palsied populations suffer greater neonatal damage to language-generative cortical tissue than is generally supposed, or else that left cerebral dominance in the neonate is unexpectedly capricious.

\section{References}

Basser, L. S. (1962). Hemiplegia of early onset and the faculty of speech with special reference to the effects of hemispherectomy. Brain, 85, 427-460.

Blumstein, S., Goodglass, H., and Tartter, V. (1975). The reliability of ear advantage in dichotic listening. Brain and Language, 2, 226-236.

Branch, C., Milner, B., and Rasmussen, T. (1964). Intracarotid sodium amytal for the lateralization of cerebral speech dominance. Journal of Neurosurgery, 21, 399-405.

Geschwind, N., and Levitsky, W. (1968). Human brain; left-right asymmetries in temporal speech region. Science, 161, 186-187.

Quinn, P. T. (1972). Stuttering: cerebral dominance and the dichotic word test. Medical Journal of A ustralia, 2, 639-643.

Quinn, P. T. (1975). The Investigation of Neurological Factors in Stutterers. PhD Thesis, University of New South Wales, Australia.

Wada, J. A. (1974). Morphologic asymmetry of human cerebral hemispheres: temporal and frontal speech zones in 100 adult and 100 infant brains. Neurology (Minneapolis), 24, 349.

Witelson, S. F., and Pallie, W. (1973). Left hemisphere specialization for language in the newborn. Brain, 96, 641-646. 